\title{
Trifluoroacetic acid: a unique solvent for atom transfer radical cyclization reactions
}

\author{
Tao Wu, Hui Yu, and Chaozhong Li* \\ Shanghai Institute of Organic Chemistry, Chinese Academy of Sciences, 354 Fenglin Road, \\ Shanghai 200032, P. R. China \\ E-mail: clig@mail.sioc.ac.cn
}

\section{Dedicated to Professor Chengye Yuan on the occasion of his $80^{\text {th }}$ birthday}

(received 30 Apr 04; accepted 30 June 04; published on the web 07 July 04)

\begin{abstract}
Triethylborane-initiated atom transfer radical cyclization reactions of various allyl or 3-butenyl iodoacetates could be efficiently carried out at room temperature with trifluoroacetic acid as the solvent. Compared to water as the solvent, trifluoroacetic acid has better solubility for organic substrates and might also function as an acid catalyst.
\end{abstract}

Keywords: Trifluoroacetic acid, radical, cyclization, solvent

\section{Introduction}

The past two decades have witnessed a rapid growth in intramolecular free radical cyclization reactions and their application in organic synthesis. ${ }^{1-9}$ Cyclization $^{10}$ of $\alpha$-carbonyl radicals leading to the formations of lactones, lactams, and cycloalkanones has received considerable attention because of its great potential in natural product synthesis. Several methods have been developed to carry out these transformations, including the tin hydride method, the halogen atom transfer method with bis(tributyltin) or triethylborane, and the organomercurial method.

Of these cyclization reactions, 5-exo cyclization of $\alpha$-ester radicals leading to the formations of $\gamma$-lactones is the most widely studied type of reaction. In order to have efficient cyclization, fast tautomerism between s-trans and s-cis rotomers of the $\alpha$-ester radicals is essential because the cyclization requires the s-cis conformations of higher energy. Several techniques have been developed for these reactions, including temperature effect, high dilution effect and solvent effect. High dilution increases the possibility of cyclization by inhibiting intermolecular oligomerization. ${ }^{11}$ Increasing the reaction temperature facilitates cyclization by allowing the faster tautomerism between s-trans and s-cis conformations of the radicals, as demonstrated by Curran and coworkers. ${ }^{12}$ For example, the reaction of allyl iodoacetate $(1 \mathbf{a})$ in benzene $(0.03 \mathrm{M})$ 
at $80{ }^{\circ} \mathrm{C}$ afforded the cyclization product $2 \mathrm{a}$ in $43 \%$ yield while no $2 \mathrm{a}$ could be formed when the reaction was performed at room temperature in benzene. More recently, Oshima and coworkers showed that water is a powerful solvent for atom transfer radical cyclization reactions. ${ }^{13-14}$ As a result, reaction of $1 \mathrm{a}$ in water $(0.03 \mathrm{M})$ at room temperature gave the expected cyclization product 2a in $67 \%$ yield. However, these reactions suffer from the low solubility of the substrates in water. For substrates having a longer alkyl (more than three carbons) chain, the reaction yield was significantly lowered. We envisioned that, by raising the solubility of substrates in the water solution, higher yields of cyclization products might be achieved. Herein we report that trifluoroacetic acid act as an excellent co-solvent for the atom transfer cyclization reactions in water. Moreover, trifluoroacetic acid alone serves as a remarkable solvent for these radical cyclization reactions.

\section{Results and Discussion}

We chose allyl iodoacetate 1a as the model substrate. For the ease of comparison, the substrate concentration was set at $0.03 \mathrm{M}$ in all the cases. The triethylborane-initiated radical reaction of 1a was carried out in various solvents at room temperature (Equation 1) and the results are summarized in Table 1.

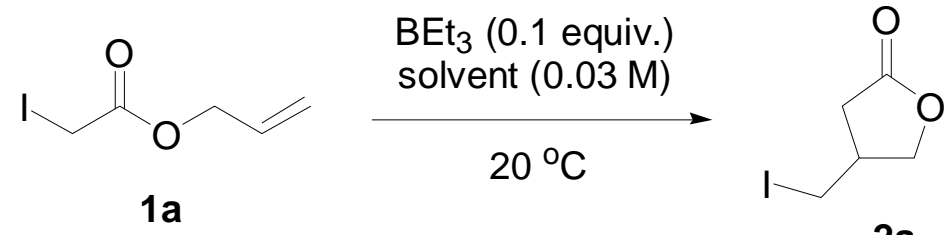

Table 1. Cyclization of $1 \mathrm{a}$ in various solvents at $20{ }^{\circ} \mathrm{C}$

\begin{tabular}{ccc}
\hline Entry & Solvent & Yield $(\%)^{\mathrm{a}}$ \\
\hline 1 & $\mathrm{H}_{2} \mathrm{O}$ & $43\left(67^{\mathrm{b}}\right)$ \\
2 & $\mathrm{H}_{2} \mathrm{O} / \mathrm{C}_{2} \mathrm{H}_{5} \mathrm{OH}(1: 1)$ & 21 \\
3 & $\mathrm{H}_{2} \mathrm{O} / \mathrm{DMSO}(1: 1)$ & 25 \\
4 & $\mathrm{H}_{2} \mathrm{O} / \mathrm{CH}_{3} \mathrm{COCH}_{3}(1: 1)$ & 26 \\
5 & $\mathrm{H}_{2} \mathrm{O} / \mathrm{CF}_{3} \mathrm{CO}_{2} \mathrm{H}(1: 1)$ & 53 \\
6 & $\mathrm{H}_{2} \mathrm{O} / \mathrm{CF}_{3} \mathrm{CO}_{2} \mathrm{H}(1: 2)$ & 51 \\
7 & $\mathrm{CF}_{3} \mathrm{CO}_{2} \mathrm{H}$ & 47 \\
\hline
\end{tabular}

${ }^{\mathrm{a}}$ Isolated yield based on $1 \mathrm{a} .{ }^{\mathrm{b}}$ Reference 14 .

As can be seen in Table 1, the use of acetone, ethanol or DMSO as the co-solvent resulted in a significant decrease in the yield of cyclization product 2a (entries $2-4$, Table 1). However, the addition of trifluoroacetic acid in water (1:1, v:v) afforded the cyclization product $\mathbf{2 a}$ in $53 \%$ 
yield (entry 5, Table 1). Increasing the ratio of trifluoroacetic acid to water showed almost no difference in the product yield. Moreover, the reaction of 1a in pure trifluoroacetic acid led to $47 \%$ yield of 2a (entry 7, Table 1). The reaction was fast and complete within an hour and the result was easily reproducible. On the other hand, the reaction of 1a in pure water was difficult to be reproduced.

We then tested various allyl iodoacetates 1a-1g in the mixed solvent of trifluoroacetic acid and water or in trifluoroacetic acid alone and the results are summarized in Table 2. For the ease of comparison, the results in water are also listed in Table 2.

Table 2. Radical cyclization reactions of allyl iodoacetates 1a-g in trifluoroacetic acid

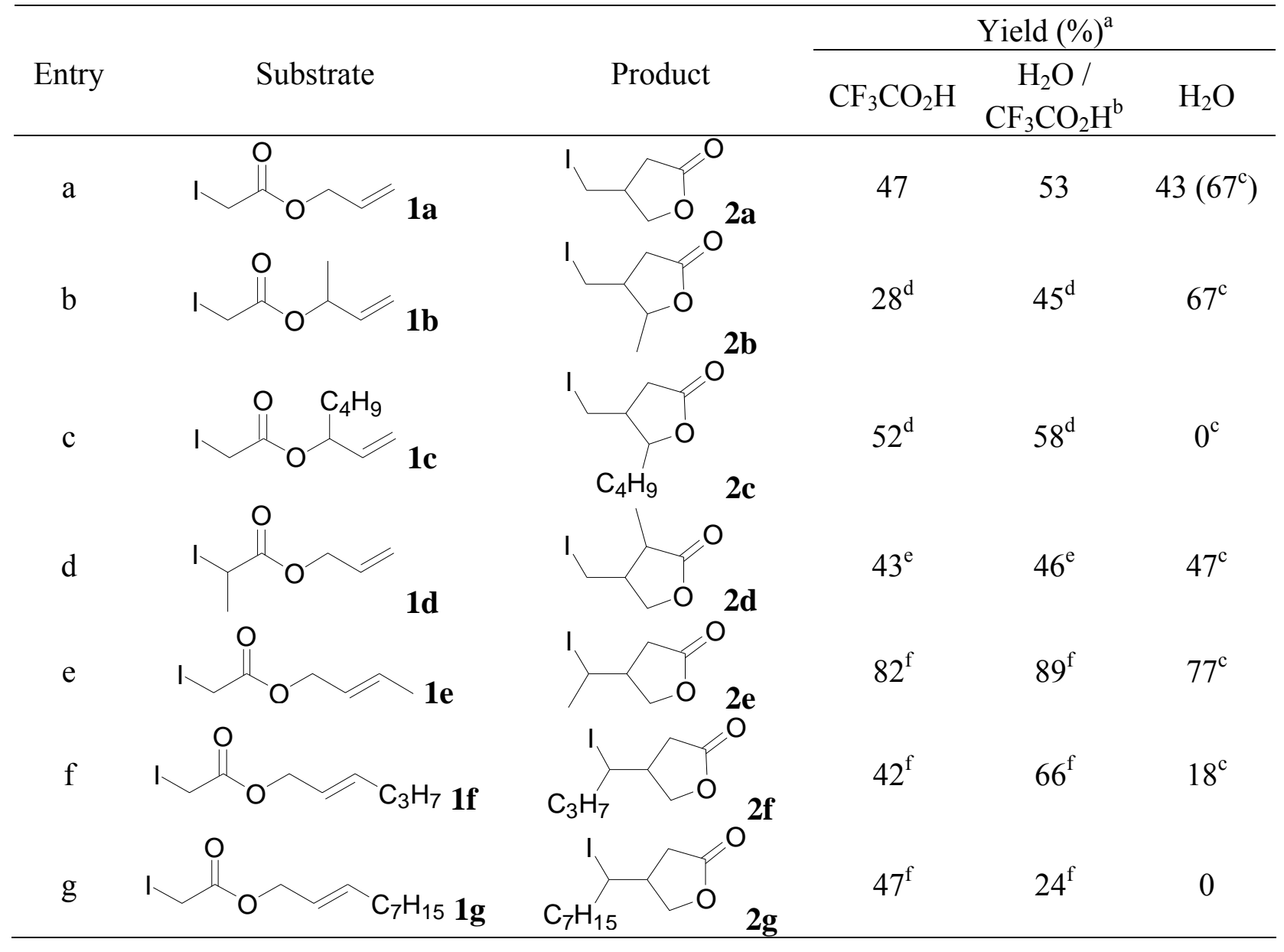

${ }^{\mathrm{a}}$ Isolated yield based on $1 .{ }^{\mathrm{b}} 1: 1$ ratio. ${ }^{\mathrm{c}}$ Reference $14 .{ }^{\mathrm{d}}$ cis $: \operatorname{trans}=10: 90 .{ }^{\mathrm{e}}$ cis $:$ trans $=5: 95 .{ }^{\mathrm{f}}$ Two stereoisomers in a 1:1 ratio.

In all the cases tested, moderate to good yields of cyclization products were achieved when trifluoroacetic acid was used as a co-solvent with water or as the only solvent. The advantage of trifluoroacetic acid over water becomes evident when the substrate bears a long alkyl substituent. For example, the reaction of substrate 1c having a butyl substituent in trifluoroacetic acid gave 
the cyclized product $2 \mathrm{c}$ in $52 \%$ yield, while the same reaction in water gave no expected product at all (entry c, Table 2). While a clear trend in the decrease of product yield was observed in water when the terminal alkyl substituent in the substrates became longer, the corresponding product yield was not significantly affected when trifluoroacetic acid was used (entries e-g, Table 2). Apparently this should be ascribed to the better solubility of substrates in trifluoroacetic acid than in water.

We then extended the above solvent system into the cyclization reactions of 3-butenyliodoacetates 3a-3d (Equation 2) and the results are summarized in Table 3.

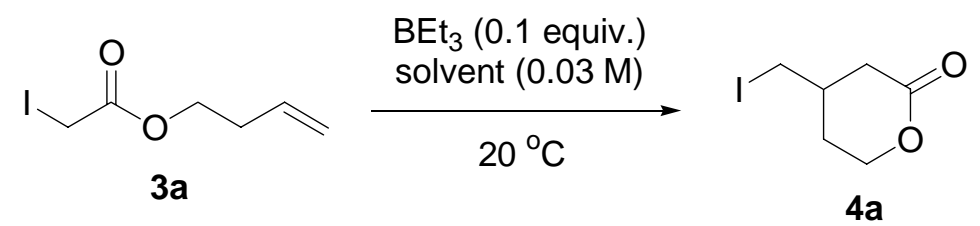

Table 3. Radical cyclization reactions of 3-butenyl iodoacetates 3a-d in trifluoroacetic acid

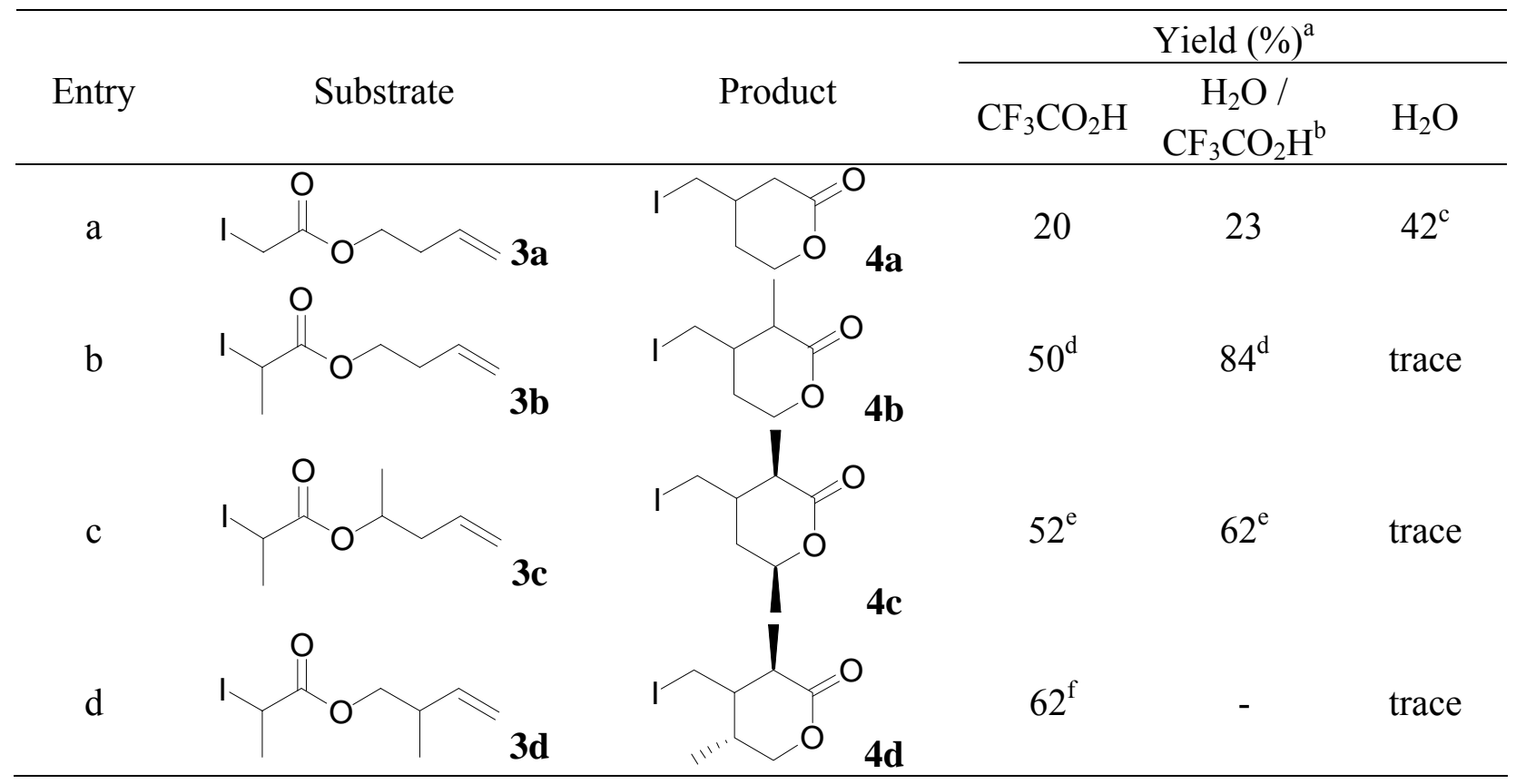

${ }^{\mathrm{a}}$ Isolated yield based on $3 .{ }^{\mathrm{b}} 1: 1$ ratio. $^{\mathrm{c}}$ Reference $14 .{ }^{\mathrm{d}}$ cis $:$ trans $=85: 15 .{ }^{\mathrm{e}} 3,4$-cis $:$ trans $=93$ : 7. ${ }^{\mathrm{f}} 3,4$-cis:trans $=88: 12$.

Although a lower yield (20\%) of $\mathbf{4 a}$ was obtained in trifluoroacetic acid than in water (42\%), the substrates 3b-3d with a methyl substituent $\alpha$ to the carbonyl gave good yields of the expected product $\delta$-lactones in trifluoroacetic acid, while the same reactions in water produced only a trace $(<5 \%)$ amount of the cyclization products. The dramatic difference between trifluoroacetic acid and water as solvent might be ascribed to the acid character of the former, as these atom transfer radical cyclization reactions are usually promoted by Lewis acids. ${ }^{15-16}$ 
In conclusion, we have demonstrated that trifluoroacetic acid serves as a remarkable solvent in the atom transfer radical cyclization reactions. The unique effect of trifluoroacetic acid resulted from its good solubility towards organic substrates and the possible role of acid catalysis. We are currently exploring the performance of trifluoroacetic acid in other types of radical cyclization systems.

\section{Experimental Section}

General Procedures. NMR spectra were recorded in $\mathrm{CDCl}_{3}\left({ }^{1} \mathrm{H}\right.$ at 300 or $400 \mathrm{MHz}$ and ${ }^{13} \mathrm{C}$ at $75.47 \mathrm{MHz}$ ) using TMS as the internal standard. 2D NMR spectra were obtained with a Bruker DRX-400 spectrometer. EIMS (70 eV) were obtained with Finnigan 4000 (GC mode) and Kratos MS-50 spectrometers. Most products were isolated by column chromatography on silica gel with hexane - ethyl acetate in appropriate ratio as the eluent.

\section{Typical procedure for atom transfer annulation reactions}

Allyl iodoacetate 1a $(224 \mathrm{mg}, 1 \mathrm{mmol})$ was placed in a $50 \mathrm{~mL}$ flask, and a mixture of trifluoroacetic acid and water (1:1, v:v) was added under nitrogen atmosphere. Triethylborane $\left(0.10 \mathrm{~mL}, 0.10 \mathrm{mmol}, 1.0 \mathrm{M}\right.$ solution in $\left.\mathrm{CH}_{2} \mathrm{Cl}_{2}\right)$ was then introduced. Air $(5 \mathrm{~mL})$ was injected via syringe into the flask. The resulting mixture was stirred at room temperature and monitored by TLC. When the substrate was consumed, the product solution was extracted with $\mathrm{CH}_{2} \mathrm{Cl}_{2}$ $(4 \times 100 \mathrm{~mL})$. The $\mathrm{CH}_{2} \mathrm{Cl}_{2}$ solution was then neutralized with $\mathrm{NaHCO}_{3}$ solution, washed with brine and dried over anhydrous $\mathrm{Na}_{2} \mathrm{SO}_{4}$. After removal of the solvent under reduced pressure, the crude product was purified by column chromatography on silica gel with ethyl acetate - hexane $(1: 1, \mathrm{v}: \mathrm{v})$ as the eluent to afford pure $2 \mathrm{a}$ as a yellowish liquid. Yield: $120 \mathrm{mg}(53 \%)$. The spectra were identical with those reported in the literature. ${ }^{12}$

4-(1-Iodooctyl)dihydro-2(3H)-furanone (2g). Mixture of two stereoisomers in a 1:1 ratio. One isomer: ${ }^{1} \mathrm{H}$ NMR (300 MHz, $\mathrm{CDCl}_{3}$ ): $\delta 4.47$ (dd, $\left.J=7.8,9.3 \mathrm{~Hz}, 1 \mathrm{H}\right), 3.97-4.07(\mathrm{~m}, 2 \mathrm{H}), 2.62-$ $2.81(\mathrm{~m}, 2 \mathrm{H}), 2.34(\mathrm{dd}, J=9.3,8.4 \mathrm{~Hz}, 1 \mathrm{H}), 1.64-1.82(\mathrm{~m}, 2 \mathrm{H}), 1.54-1.63(\mathrm{~m}, 2 \mathrm{H}), 1.27-1.44(\mathrm{~m}$, $8 \mathrm{H}), 0.88(\mathrm{t}, J=6.5 \mathrm{~Hz}, 3 \mathrm{H}) .{ }^{13} \mathrm{C} \mathrm{NMR}\left(\mathrm{CDCl}_{3}\right): \delta 174.7,73.0,42.1,37.8,37.2,34.0,30.7,28.3$, 28.0, 27.6, 21.6, 13.1. MS (m/z): $324\left(\mathrm{M}^{+}, 1\right), 137$ (100), 95 (37), 81 (42), 69 (21), 67 (24), 55 (34), 43 (23), 41 (38). Anal. Calcd for $\mathrm{C}_{12} \mathrm{H}_{21} \mathrm{IO}_{2}$ : C, 44.46; H, 6.53. Found: C, 44.62; H, 6.55. The other isomer: ${ }^{1} \mathrm{H}$ NMR $\left(300 \mathrm{MHz}, \mathrm{CDCl}_{3}\right): \delta 4.38(\mathrm{dd}, J=7.9,9.2 \mathrm{~Hz}, 1 \mathrm{H}), 3.99-4.08(\mathrm{~m}$, $2 \mathrm{H}), 2.52-2.63(\mathrm{~m}, 2 \mathrm{H}), 2.42(\mathrm{dd}, J=9.9,10.0 \mathrm{~Hz}, 1 \mathrm{H}), 1.69-1.80(\mathrm{~m}, 1 \mathrm{H}), 1.44-1.60(\mathrm{~m}, 3 \mathrm{H})$, $1.21-1.36(\mathrm{~m}, 8 \mathrm{H}), 0.82(\mathrm{t}, J=6.5 \mathrm{~Hz}, 3 \mathrm{H}) .{ }^{13} \mathrm{C} \mathrm{NMR}\left(\mathrm{CDCl}_{3}\right): \delta 174.3,71.1,41.8,38.4,37.1$, 33.9, 30.7, 28.7, 28.0, 27.6, 21.6, 13.0. MS (m/z): $324\left(\mathrm{M}^{+}, 1\right), 307$ (17), 197 (16), 179 (26), 137 (100), 95 (32), 81 (35), 55(20), 41 (26). Anal. Calcd for $\mathrm{C}_{12} \mathrm{H}_{21} \mathrm{IO}_{2}$ : C, 44.46; H, 6.53. Found: $\mathrm{C}$, 44.77; H, 6.70 . 


\section{Acknowledgements}

This project was supported by the National Natural Science Foundation of China.

\section{References}

1. Giese, B. Radicals in Organic Synthesis: Formation of Carbon-Carbon Bonds; Pergamon: Oxford, UK, 1986.

2. Curran, D. P. Synthesis 1988, 417 and 489.

3. Jasperse, C. P.; Curran, D. P.; Fevig, T. L. Chem. Rev. 1991, 91, 1237.

4. Melikyan, G. G. Synthesis 1993, 833.

5. Iqbal, J.; Bhatia, B.; Nayyar, N. K. Chem. Rev. 1994, 94, 519.

6. Snider, B. B. Chem. Rev. 1996, 96, 339.

7. Curran, D. P.; Porter, N. A.; Giese, B. Stereochemistry of Radical Reactions, VCH: Weinheim, Germany, 1996.

8. Gansauer, A.; Bluhm, H. Chem. Rev. 2000, 100, 2771.

9. Renaud, P.; Sibi, M. P., Eds.; Radicals in Organic Synthesis; Wiley-VCH: Weinheim, Germany, 2001.

10. Giese, B.; Kopping, B.; Gobel, T.; Dickhaut, J.; Thoma, G.; Kuliche, K. J.; Trach, F. In Organic Reactions; Wiley: New York, 1996; Vol. 48, p 301.

11. Barth, F.; O-Yang, C. Tetrahedron Lett. 1990, 31, 1211.

12. Curran, D. P.; Tamine, J. J. Org. Chem. 1991, 56, 2746.

13. Yorimitsu, H.; Nakamura, T.; Shinokubo, H.; Oshima, K. J. Org. Chem. 1998, 63, 8604.

14. Yorimitsu, H.; Nakamura, T.; Shinokubo, H.; Oshima, K.; Omoto, K.; Fujimoto, H. J. Am. Chem. Soc. 2000, 122, 11041.

15. For a review article, see: Renaud, P.; Gerster, M. Angew. Chem., Int. Ed. 1998, 37, 2562.

16. Fang, X.; Xia, H.; Yu, H.; Dong, X.; Chen, M.; Wang, Q.; Tao, F.; Li, C. J. Org. Chem. 2002, 67, 8481 . 